\title{
PERFORMANCE ANALYSIS OF THE ROUTING PROTOCOLS FOR VIDEO STREAMING OVER MOBILE AD HOC NETWORKS
}

\author{
Muhammad Shaffatul Islam \\ Khulna University of Engineering \\ and Technology, Khulna \\ Bangladesh
}

\author{
Md. Adnan Riaz \\ Technical University of \\ Munich, Munich \\ Germany
}

\author{
Mohammed Tarique \\ Ajman University of \\ Science and Technology, \\ Fujairah, UAE
}

\begin{abstract}
Mobile Ad hoc Networks (MANETs) are very considered attractive for many applications. Routing protocol is considered as the most important element of MANET. However, media streaming over MANET is a quite demanding task. In this paper the performances of MANET routing protocols have been investigated for video applications. Some popular routing protocols namely Dynamic Source Routing (DSR), Ad hoc On-demand Distance Vector (AODV), Temporally-Ordered Routing Algorithm (TORA), Optimized Link State Routing Protocol (OLSR), and Geographic Routing Protocol (GRP) have been considered in this paper. A comparative performance analysis of these routing protocols has been presented in this paper for supporting video streaming applications.
\end{abstract}

Key words - Mobile Ad hoc Networks, routing protocols, video streaming, DSR, AODV,

TORA, OSLR, GRP, QoS.

\section{INTRODUCTION}

Mobile Ad hoc Network (MANET) has been an active area of researches for the last few years. The driving force behind all these researches is to provide the customers with the network support "at anywhere and at any time". MANETs are self-organizing and self-configuring. No infra-structure is needed to build and administer MANETs. It works in a multi-hop fashion. A mobile node not only transmits its own packets but also forwards packets for other mobile nodes [1][2]. MANETs have become a popular subject of active researches as the usages of the notebooks and 802.11/Wi-Fi network have become widespread [2]. In this modern age mobile modules (i.e., laptop, mobile phones, and PDA) have shown great improvements in terms of performance and memory capacity [6]. Advancements in technology have made it possible to utilize these small, mobile and wireless modules suitable for the formation and maintenance of MANETs at utmost efficiency [2],[5],[6]. Many ground breaking applications of MANETs have been suggested in the literatures. One of them is to provide data communication services during rescue and emergency operations. In such operations, infrastructure might not exist (e.g., 
International Journal of Computer Networks \& Communications (IJCNC) Vol.4, No.3, May 2012

remote areas) or be partially or entirely destroyed (e.g., an earthquake) [1],[2],[5],[6]. In such environments multimedia services such as live video feeds or video conferencing are essential for the rescue personnel. But, supporting these types of multimedia services over MANET is not an easy task. There are many research challenges that are yet to be solved [8]. Video streaming in MANETs is a challenging task due to the combined effects of wireless communications characteristics (i.e., multipath fading and shadowing, interferences, and collisions) and topology maintenance in the presence of node mobility. All of these effects have negative impacts on the on-going video sessions. In particular, topology changes provoke intermittent connectivity and hence cause large packet loss bursts. Thus, supporting the video transmission systems in MANET is a real challenge for the network designers [6],[8]. Multimedia centric MANET routing protocols and adaptive video coding solve the challenges to some extent. These approaches do not often follow the principles of layering and hence they are incompatible with the existing technology and protocols, which are still in their infancy level to be used by the users [9]. In fact, the solutions adopted by the infrastructure based cellular or Wi-Fi networks are not suitable for MANETs since the effectiveness of the video packets delivery is highly dependent on the underlying routing protocol [6],[9]. Therefore, finding a suitable routing protocol for supporting video traffic is an important issue and this is the main topic of this work.

In this paper we have investigated various routing protocols in order to find a suitable routing protocol for transmitting video stream over a real MANET scenario for both small area and large area via simulation. Many MANET routing protocols have been proposed and investigated in the literatures. In this work, we focus on the following routing protocols (1) Dynamic Source Routing (DSR), (2) Ad-hoc On-demand Distance Vector (AODV), (3) Temporally-Ordered Routing Algorithm (TORA), (4) Optimized Link State Routing Protocol (OLSR), and (5) Geographic Routing Protocol (GRP). We have analyzed and compared the video streaming performances over these routing protocols considering different Quality of Service (QoS) performance metrics such as throughput, wireless LAN delay, end-to-end delay and packet delay variation. The rest of the paper is organized as follows: Section 2 presents some related works found in the literatures. Section 3 contains brief descriptions of the investigated routing protocols. Simulation models and results are presented in Section 4. The paper is concluded with section 5 .

\section{RELATED WORK}

Addressing video streaming performance in MANETs from different perspectives can be found in the literatures. In [11] the authors evaluate the performance of H.264 protocol using two routing protocols namely Neighbor-Aware Cluster Head (NACH) and Dynamic Source Routing (DSR) protocols. The authors show that it is feasible to have video over MANETs within an average distance of 6 hops, and requiring 5.5 Mbps on average. The main disadvantage of this work is that the delay and throughput performances have not been investigated. In [11] the author analyzed the throughput of the video applications running over MANETs. The authors considered three different routing protocols in their investigations. In this study two different networks have been investigated. One network is consisting of 25 nodes and the other one is consisting of 81 nodes. The network area is $800 \mathrm{~m}$ by $1600 \mathrm{~m}$. Comparative study has been made between two PHY layer technologies namely IEEE802.11g at 54 Mbps and IEEE802.11a at $11 \mathrm{Mbps}$. Other performance issues like packet end-to-end delay, delay variation and quality factor have not been considered in [11]. In [12], the authors proposed a novel service-aware reputation based routing protocol for video-streaming over MANETs named RDSR-V (Reliable Dynamic Source Routing for Video) which outperforms both standard Dynamic Source Routing (DSR) and OCEAN (a generic reputation-based mechanism). In [13] the authors have considered not only UDP-based video streaming but also TCP-based video streaming using 
International Journal of Computer Networks \& Communications (IJCNC) Vol.4, No.3, May 2012

Optimized Link State Routing Protocol (OLSR). It was shown that these two protocols are suitable for the quick reconfiguration of path breaks and for saving bandwidth. Other established routing protocols have not been analyzed in this work. In paper [14], the impacts of mobility, traffic type and traffic intensity on the performance of a multimedia traffic over MANET by using DSR protocol are evaluated. The performance parameters used are namely the end-to-end delay, the packet delivery ratio and the normalized routing load. In this paper, we have analyzed some of the popular routing protocols namely AODV, DSR, OLSR, TORA and GRP. The performances of these routing protocols have been investigated for video transmission (both in small scale and large scale scenarios) in terms of some popularly used QoS parameters.

\section{ROUTING PROTOCOLS FOR MANETS}

Designing an efficient routing protocol for MANET is an exigent problem. The main objectives of an efficient routing protocol are (i) to discover paths between a source and a destination, and (ii) to maintain these discovered paths. It is imperative to fulfill these two objectives by using minimum overhead /control messages. Node mobility is one of major obstacles that a routing protocol has to deal with. An efficient routing protocol should also have some other desired characteristics namely distributed operation, loop-free path discovery, and demand based operation. It should also support unidirectional link, maintain many routes and have a "sleep" period operation [2],[15],[16]. Keeping these issues in mind researchers has proposed several routing protocols for MANET. These MANET routing protocols can be classified as proactive (table-driven) and reactive (on-demand) depending on how they react to topology changes [3]. In proactive routing protocols the route information among the nodes is periodically exchanged. Each node is allowed to build a global knowledge of the network independently. The most typical representative of the proactive routing protocol is Dynamic Destination Sequenced Distance Vector (DSDV). In reactive approach the exchange of route information is limited. It works on-demand in a sense that a mobile node discovers a route when it has some packets to send to another node. The most cited representatives of the reactive routing protocol are Dynamic Source Routing Protocol (DSR) and Ad hoc On Demand Distance Vector (AODV) [3]. Reactive routing protocols use flooding methods to discover a route and waste valuable resource like bandwidth. To overcome these shortcomings another two protocols have been proposed in the literatures namely (i) mixed routing protocol (based on the combination of proactive routing protocol and reactive routing protocol), and (ii) position-based routing protocol. A comprehensive study on other MANET routing protocols can in found in [1][2],[17]. We limit this effort to DSR, AODV, Temporally Ordered Routing Algorithm (TORA), Optimized Link State Routing (OLSR) and Geographic Routing Protocol (GRP). Brief descriptions of the investigated routing protocols have been provided in this section for the completeness of this paper.

\subsection{Dynamic Source Routing (DSR) Protocol}

The Dynamic Source Routing (DSR) protocol [2] is a reactive routing protocol for MANETs. When a node generates packets to send them to a certain destination and it does not have a known route to that destination, this node starts a route discovery process. One advantage of DSR is that no periodic routing packets are required. DSR also has the capability to handle unidirectional links. There are two main operations in DSR, route discovery and route maintenance [2]. During the route discovery procedure, routers maintain lists of the recently seen requests to avoid repeatedly processing the same route request. Requests are discarded if they were processed recently. If a router receives a request and detects that the request contains its own ID in the list of intermediate routers, this router discards the request to avoid loops. The route maintenance procedure is used when routes become invalid due to the unpredictable 
International Journal of Computer Networks \& Communications (IJCNC) Vol.4, No.3, May 2012

movement of routers. Each router monitors the links that it uses to forward packets. Once a link is down, a route error packet is immediately sent to the initiator of the associated route. Therefore, the invalid route is quickly discarded. To handle unreliable transmissions of control messages, DSR either relies on the underlying MAC protocol to provide guaranteed delivery or it retransmits control messages for a certain number of times [2]. Since DSR is a reactive protocol, it cannot determine whether a destination is unreachable or the route request is lost. Therefore, it suffers more overhead if the underlying MAC layer does not support guaranteed delivery [18]. Since DSR discovers routes on-demand, it may perform poorly in networks with high mobility and heavy traffic loads because of high overhead packets. Scalability is said to be another disadvantage of DSR, because DSR relies on blind broadcasts (i.e., blind flooding) to discover routes [18].

\subsection{Ad Hoc on Demand Distance Vector Routing (AODV)}

The Ad hoc On-demand Distance Vector (AODV) routing protocol is also a reactive routing protocol proposed for MANET [2], [19]. Similar to DSR protocol, AODV broadcasts a route request to discover a route in a reactive mode. The difference is that in AODV, a field containing the number of hops traveled by a packet is recorded instead of a list of intermediate router addresses. Each intermediate router sets up a temporary reverse link in the process of a route discovery. This link points to the router that forwarded the request. Hence, the reply message can find its way back to the initiator when a route is discovered. When intermediate routers receive the reply, they can also set up corresponding forward routing entries. To prevent old routing information being used as a reply to the latest request, a destination sequence number (DSN) is used in the route discovery packet and the route reply packet. A higher sequence number implies a more recent route request. AODV uses the message types Route Request (RREQ), Route Replies (RREP) and Route Error (RERR) in discovering the route from a source to a destination by using UDP (user datagram protocol) packets. Route maintenance in AODV is similar to that in DSR. One advantage of AODV is that it is a loopfree routing due to the destination sequence numbers associated with routes. The AODV avoids the Bellman-Ford "count to infinity" problem. Therefore, it offers quick convergence when the ad hoc network topology changes. Similar to DSR, poor scalability is a disadvantage of AODV.

\subsection{Temporally-Ordered Routing Algorithm (TORA)}

The Temporally Ordered Routing Algorithm (TORA) is an adaptive routing protocol for multihop networks. TORA is a distributed algorithm so that routers only need to maintain knowledge about their neighbors [1] [20]. TORA also maintains states on a pre-destination basis like other distance vector algorithms. It uses a mechanism that combines reactive and proactive routing. Sources initiate route requests in a reactive mode. At the same time, selected destinations may start proactive operations to build traditional routing tables. Usually, routes to these destinations may be consistently or frequently required such as routes to gateways or servers. TORA supports multiple path routing and it minimizes the communication overhead associated with network topology changes [2]. The reason is that TORA maintains multiple paths and it does not need to discover a new route when the network topology changes unless all routes in the local route cache fail. Hence, the route used in this protocol may not always be the shortest one since a set of paths is used. TORA assigns directions to all links according to the heights of their neighboring routers in terms of upstream or downstream. A link is considered an upstream link for the "lower" neighboring router. At the same time, it is also considered a downstream link for the "higher" neighboring router. An upstream link for a router implies that data flows to the corresponding destination can only come into this router via that link. A downstream link for a router means that data flows can only leave this router to the neighboring router via this 
International Journal of Computer Networks \& Communications (IJCNC) Vol.4, No.3, May 2012

link. TORA is a complex algorithm compared to DSR. It has four operations: (i) creating routes, (ii) maintaining routes, (iii) erasing routes, and (iv) optimizing the routes [14]. The creating routes operation is responsible for selecting the proper heights for routers and forming a directed sequence of links leading to the destination in a previously undirected network. The maintaining routes operation is the process that responds to network topology changes. The operation of erasing routes is used to set routers 'heights' to NULL and set the links to undirected. TORA uses the optimizing routes function to adjust the heights of routers to improve routing. Four packets are used to perform these operations: query (QRY), update (UPD), clear (CLR), and optimization (OPT) [20].

\subsection{Optimized Link State Routing Protocol (OLSR)}

The Optimized Link State Routing (OLSR) protocol is a proactive link state routing protocol for MANETs. One key idea is to reduce control overhead by reducing the number of broadcasts as compared with pure 'flooding' mechanisms. The basic concept to support this idea in OLSR is the use of multipoint relays (MPRs) [21]. MPRs refer to selected routers that can forward broadcast messages during the flooding process. To reduce the size of broadcast messages, every router declares only a small subset of all of its neighbors. OLSR has three functions: packet forwarding, neighbor sensing, and topology discovery [21]. Packet forwarding and neighbor sensing mechanisms provide routers with information about the neighbors and offer an optimized way to flood messages in the OLSR network using MPRs. The neighbor sensing operation allows routers to diffuse local information to the whole network. Topology discovery is used to determine the topology of the entire network and to update the routing tables. OLSR uses four message types: 'Hello' message, Topology Control (TC) message, Multiple Interface Declaration (MID) message, and Host and Network Association (HNA) message [21],[22]. 'Hello' messages are used for neighbor sensing. Topology declarations are based on TC messages. MID messages contain multiple interface addresses and perform the task of multiple interface declarations. Since the hosts that have multiple interfaces connected with different subnets, HNA messages are used to declare host and associated network information. Extensions of message types may include power saving mode and multicast mode. OLSR routers periodically broadcast 'Hello' packets to one-hop neighbors. Each router builds a list of neighbors and a list of two-hop neighbors based on received 'Hello' messages. Each router also creates one MPR set and one MPR selector (MPRS) set. Routers that have non-empty MPRS lists broadcast their MPRS sets to neighbors via TC packets. Therefore, the size of control messages is reduced compared with broadcasting a list of all neighbor routers. A router rebroadcasts received packets if and only if the sender of that packet is in its MPR selector set. This helps to reduce the frequency of 'flooding'. Routers build routing tables based on received TC packets. The protocol is particularly suitable for large and dense networks. The larger and more dense a network, the more optimization can be achieved as compared to the classic link state algorithm [21],[22].

\subsection{Geographic Routing Protocol (GRP)}

The Geographic Routing Protocol (GRP) is a position-based protocol classified as Proactive Routing Protocol [24]. In GRP protocol the location of a node is marked by GPS and flooding will be optimized by quadrants [23]. Flooding location is updated on distance when the node moves and crosses neighborhood. A 'Hello' protocol will be exchanged between nodes to identify their neighbors and their positions. At the same time, by means of route locking a node can return its packet to the last node when it cannot keep on sending the packet to the next node. GRP divides a network into many quadrants to reduce route flooding [23]. The entire world is divided into quadrants from Lat, $\operatorname{Long}(-90,-180)$ to Lat, Long $(+90,+180)$. Every 
International Journal of Computer Networks \& Communications (IJCNC) Vol.4, No.3, May 2012 node knows the initial position of every other accessible node once initial 'flooding' is completed in the network. When the node moves a distance longer than a user has specified or when the node crosses a quadrant the routing flooding will be occurred [23].

\section{SIMULATION MODELS AND RESULTS}

The performances of the routing protocols supporting video stream transmission have been investigated by using OPNET simulator. The default simulation parameters used to analyze the performance of different routing protocols are listed in the Table 1

Table 1: Simulation parameters

\begin{tabular}{|l|l|}
\hline The Number of Nodes & 25 and 85 \\
\hline Network Size & $800 \mathrm{~m} \times 800 \mathrm{~m}$ and $1600 \mathrm{~m} \times 1600 \mathrm{~m}$. \\
\hline Initial Placement & Placed in row and column based manner. \\
\hline Mobility & $\begin{array}{l}\text { Random waypoint model with continuous movement } \\
\text { and maximum and minimum speed of } 5 \mathrm{~m} / \mathrm{s} \text { and } 10 \\
\text { m/s Respectively. }\end{array}$ \\
\hline Communication Model & Selection by strict channel match \\
\hline Distance Threshold & $300 \mathrm{~m}$ \\
\hline Simulation time & 600 Simulation seconds \\
\hline
\end{tabular}

The default network and simulation are used so that we can model a moderately loaded network. We choose two types of scenarios with two different area sizes to measure the performance of the application for both small and large scale inter-node distance. The protocol used and the application settings for the simulation are provided in the Table 2.

Table 2: Simulated applications and protocols used

\begin{tabular}{|l|l|l|}
\hline Physical Layer & Segmented calculation of the signal power and SNR \\
\hline MAC Layer & $\begin{array}{l}\text { IEEE802.11 DCF with transmission rate of 54Mbits/s for } \\
\text { video application }\end{array}$ \\
\hline Network Layer & AODV,DSR,TORA, OLSR and GRP \\
\hline \multirow{4}{*}{$\begin{array}{l}\text { Application Name: Video } \\
\text { stream }\end{array}$} & \multicolumn{2}{|c|}{ Low Resolution Video } \\
\cline { 2 - 3 } & Frame inter-arrival time & 10 frames/sec \\
\cline { 2 - 3 } & Frame size & $128 x 120$ pixels \\
\cline { 2 - 3 } & Type of services (ToS ) & Streaming Multimedia \\
\cline { 2 - 3 } & \multicolumn{2}{|c|}{ High Resolution Video } \\
\cline { 2 - 3 } & Frame inter-arrival time & 15 frames/sec \\
\cline { 2 - 3 } & Frame size & Streaming Multimedia \\
\cline { 2 - 2 } & Type of services (ToS ) & preels \\
\hline
\end{tabular}

The performance of the simulated results is analyzed according to different performance matrices namely (1) throughput, (2) packet end-to-end delay, (3) Wireless LAN delay, and (4) packet delay 
International Journal of Computer Networks \& Communications (IJCNC) Vol.4, No.3, May 2012 variation. We have only accounted the packet end-to-end delay of the application, but the routing delay is not considered. The overall end-to-end delay is calculated as the average of the delay of all

packets. The routing delay is not studied here since the delay is affected only at the very beginning of the video transmission. We considered two cases to be precise (a) low resolution video transmission, and (b) high resolution video transmission.

\subsection{Low resolution video transmission:}

It is observed from the simulations that for transmitting low resolution video two different routing protocols perform better in terms of throughput in different scenario.

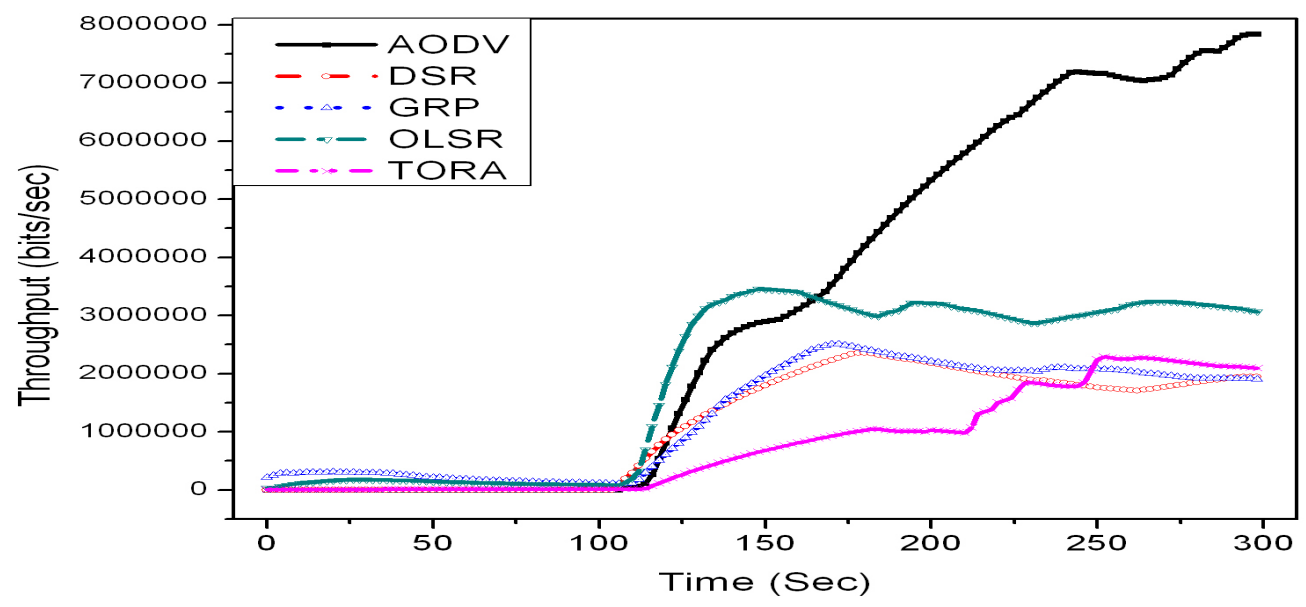

Fig. 1 Throughput for 25 nodes

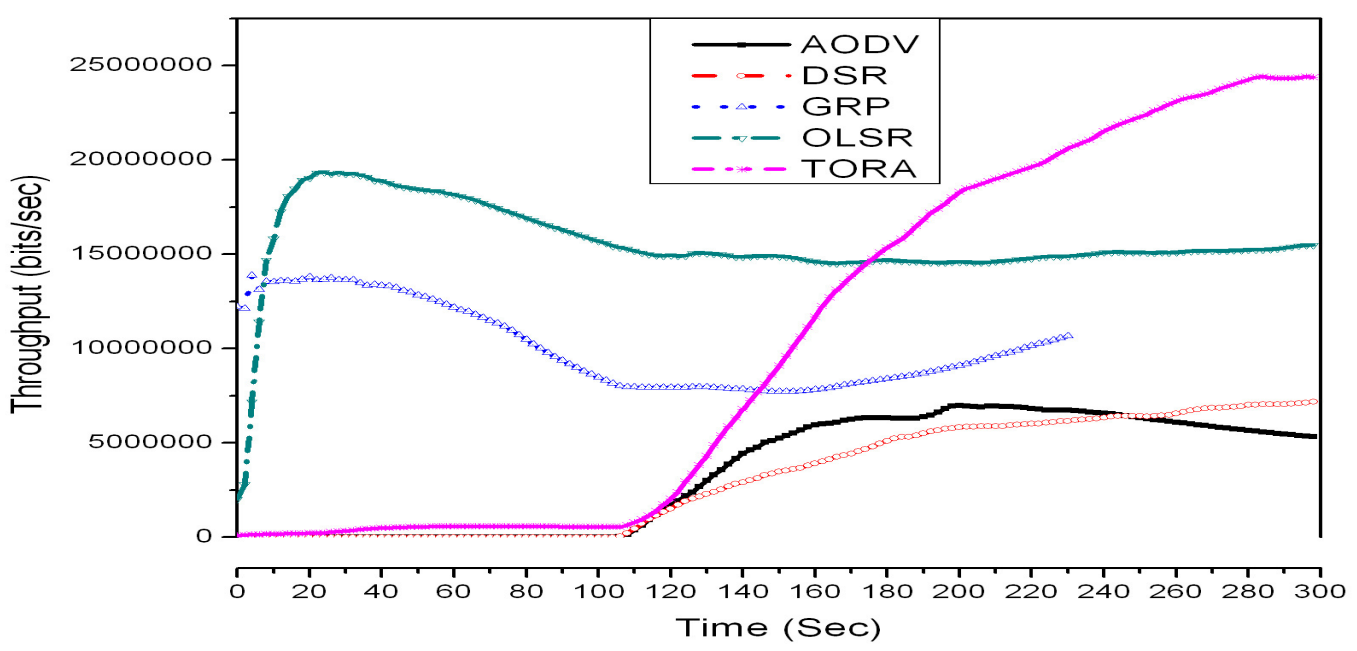

Fig. 2 Throughput for the network of 85 nodes.

In small area (Fig. 1) the throughput of AODV protocol is the highest and it increases with time of transmission whereas in large area (Fig. 2) TORA protocol outperforms other protocols and 
International Journal of Computer Networks \& Communications (IJCNC) Vol.4, No.3, May 2012

the throughput increases significantly. Besides OLSR and GRP also have significant throughput.DSR protocol has same throughput characteristics for both large and small area network which is not very high.

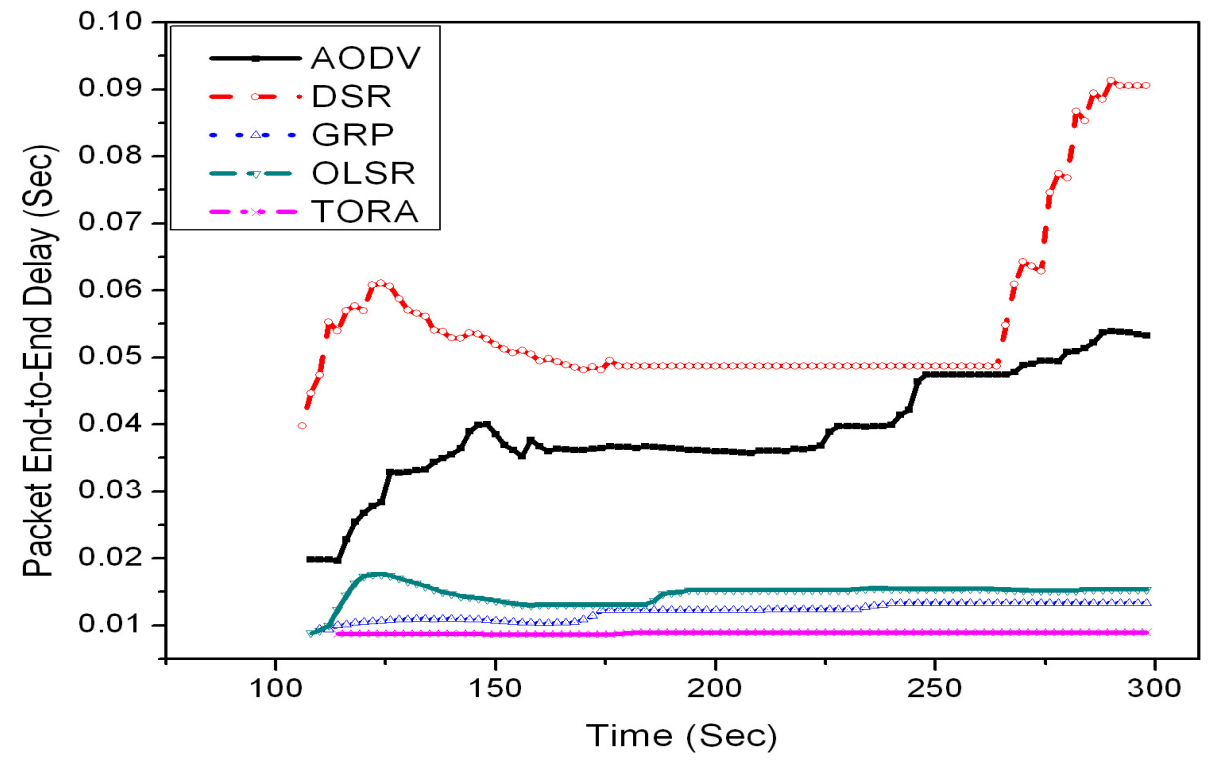

Fig. 3 Packet end-to-end delay for the network of 25 nodes.

Analyzing the data for packet end-to-end delays as shown in Fig. 3 and Fig. 4 for small area and large area respectively it is obvious that TORA protocol has the lowest end-to-end delay in both scenarios.

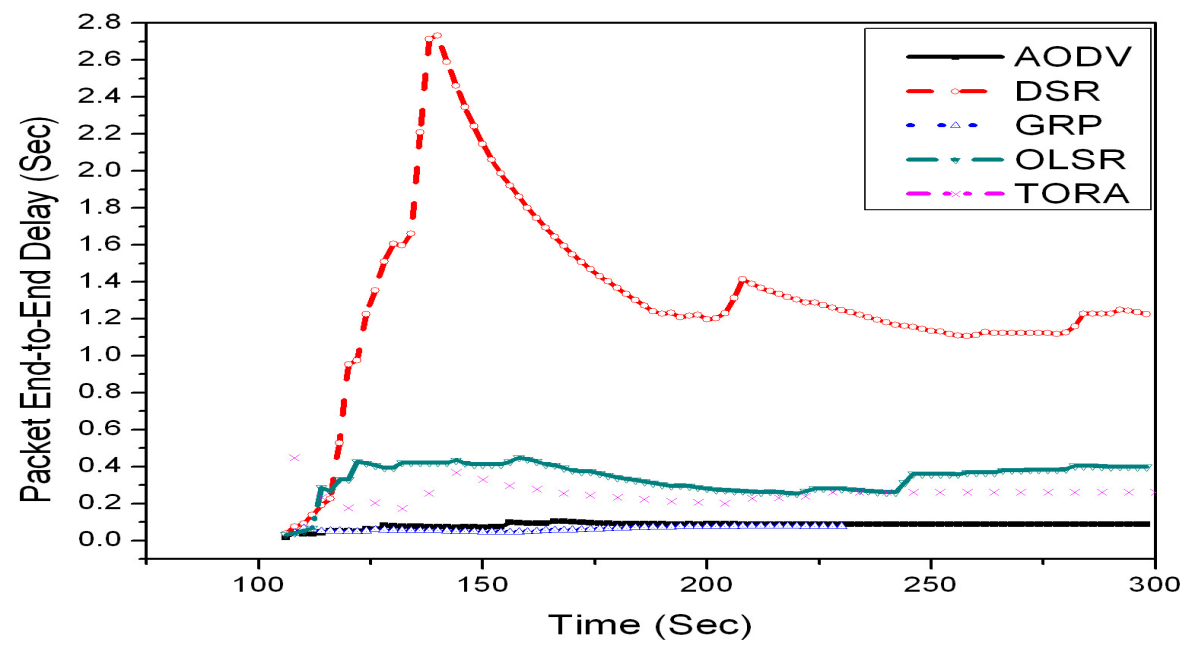

Fig. 4 Packet end-to-end delay for the network of 85 nodes.

But, DSR protocol shows the worst performance and the delay is very high compared to other protocols. The end-to-end delay is constant for both scenarios which is very important for 
International Journal of Computer Networks \& Communications (IJCNC) Vol.4, No.3, May 2012 communication whereas the end-to-end delay of DSR is nonlinear with time. The AODV protocol shows opposite behavior for small area and large area as shown in Fig. 3 and Fig. 4.

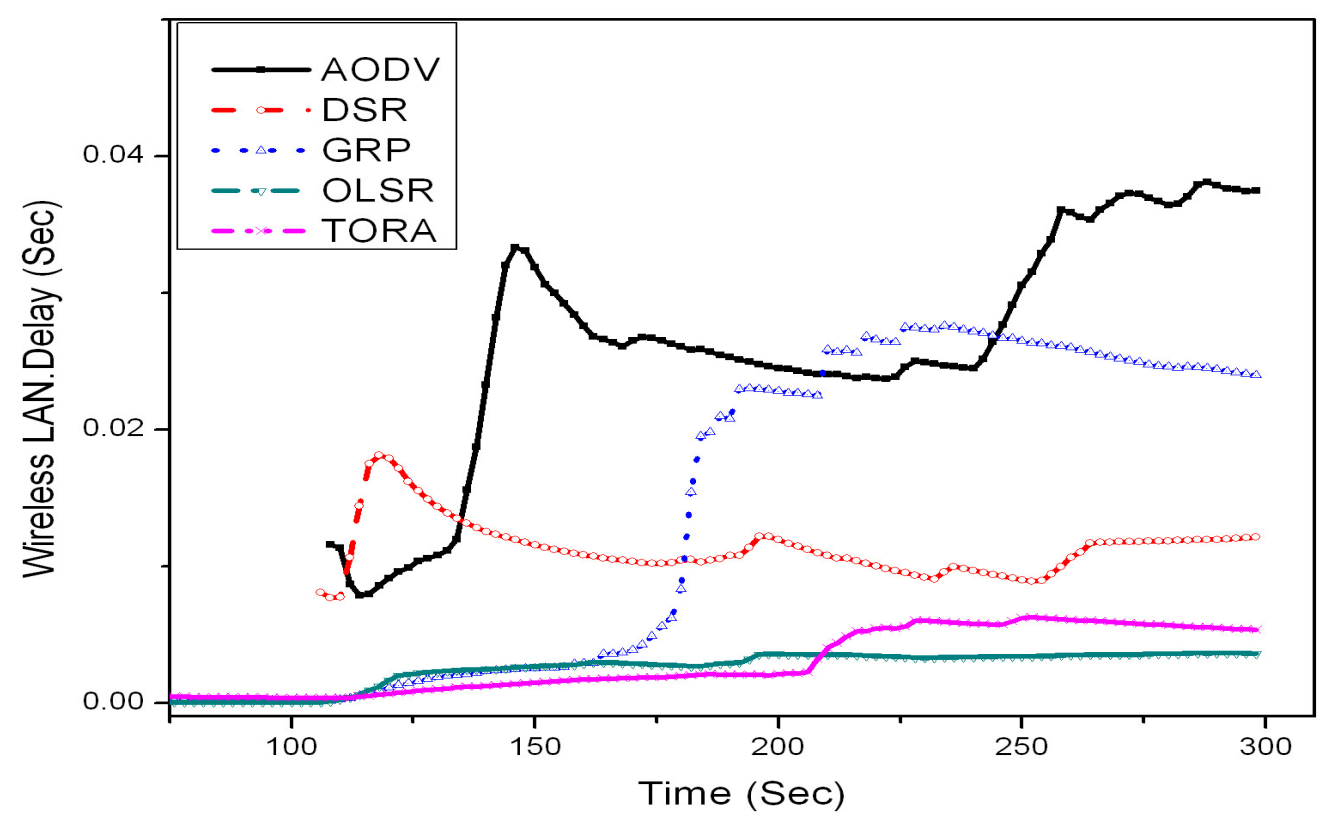

Fig 5: Wireless LAN delay for the network 25 nodes

The wireless LAN delay performances for small network and large network are depicted in Fig. 5 and Fig. 6. TORA protocol performs better compared to other protocols. The performances of other protocols are unpredictable and they demonstrate a very high delay.

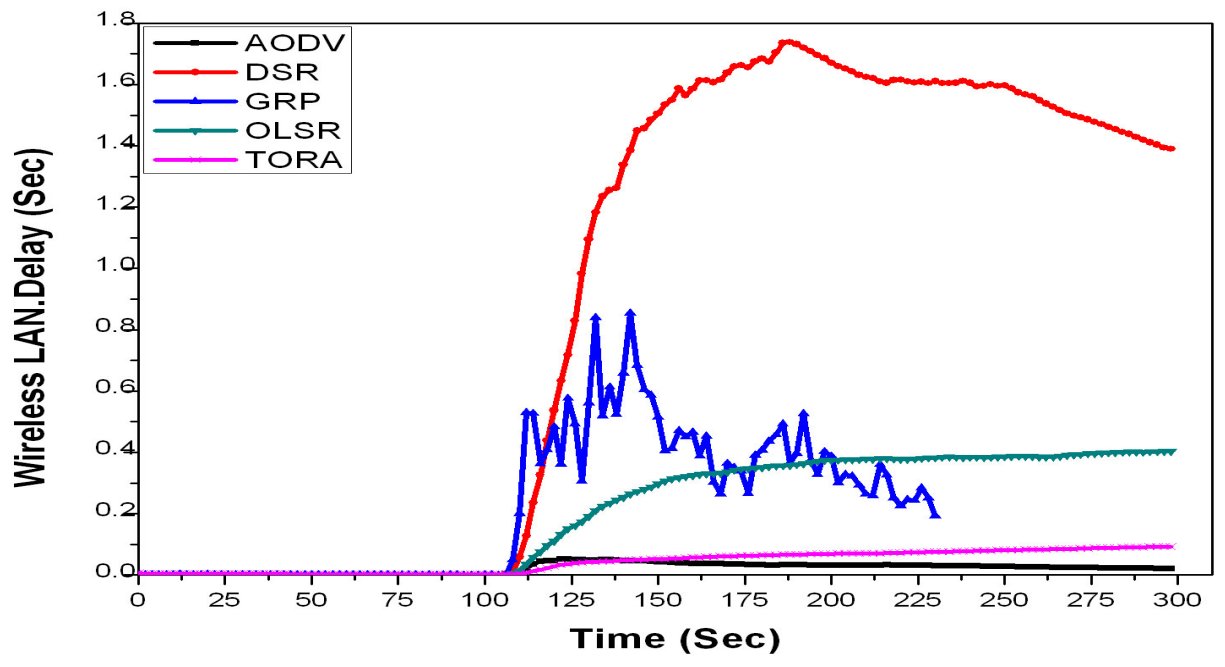

Fig. 6 Wireless LAN delay for the network of 85 nodes 
International Journal of Computer Networks \& Communications (IJCNC) Vol.4, No.3, May 2012

They also behave differently for small and large area. We can conclude that AODV is a good candidate for transmission in large area but it has the highest delay for the small network (i.e., network consisting of 25 nodes).

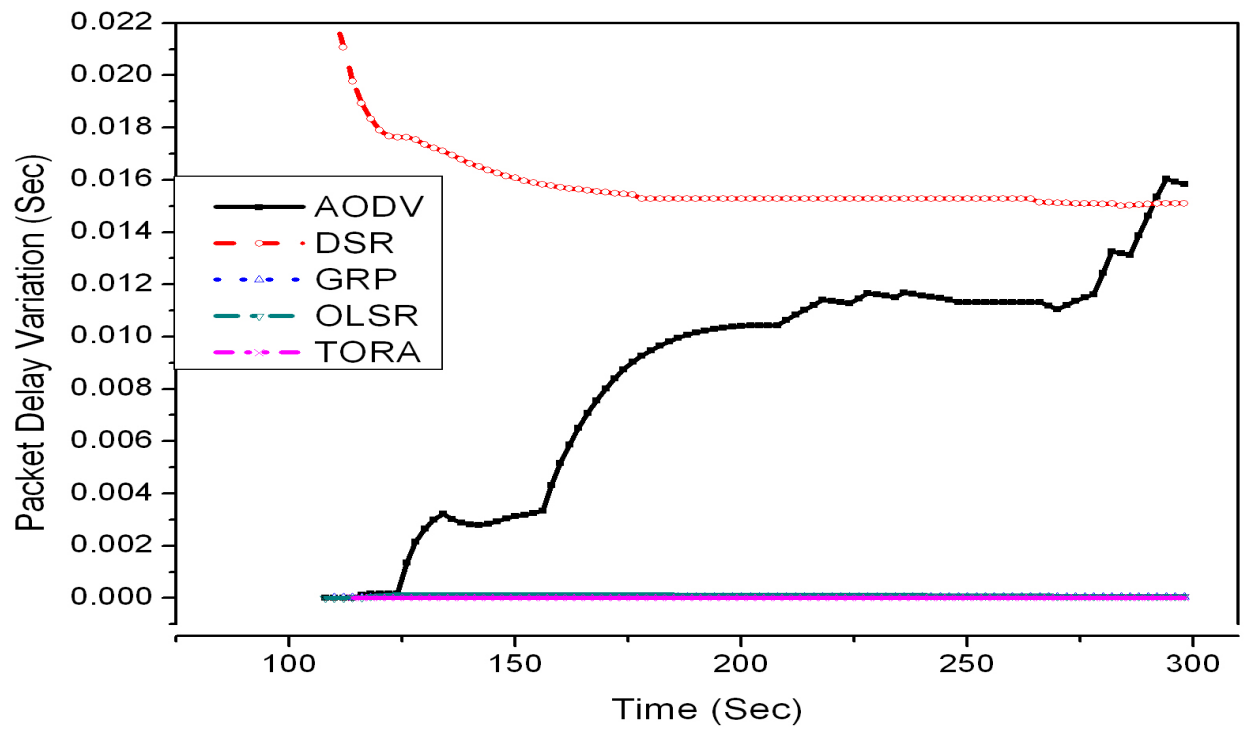

Fig. 7 Packet delay variation for the network of 25 nodes

Analyzing the packet delay variation graph for small area and large areas as depicted in Fig. 7 and Fig. 8 respectively it is seen that three protocols TORA, OLSR and GRP show similar performance whereas AODV and DSR protocols show high packet delay variations and the packet delay drastically changes with the simulation time.

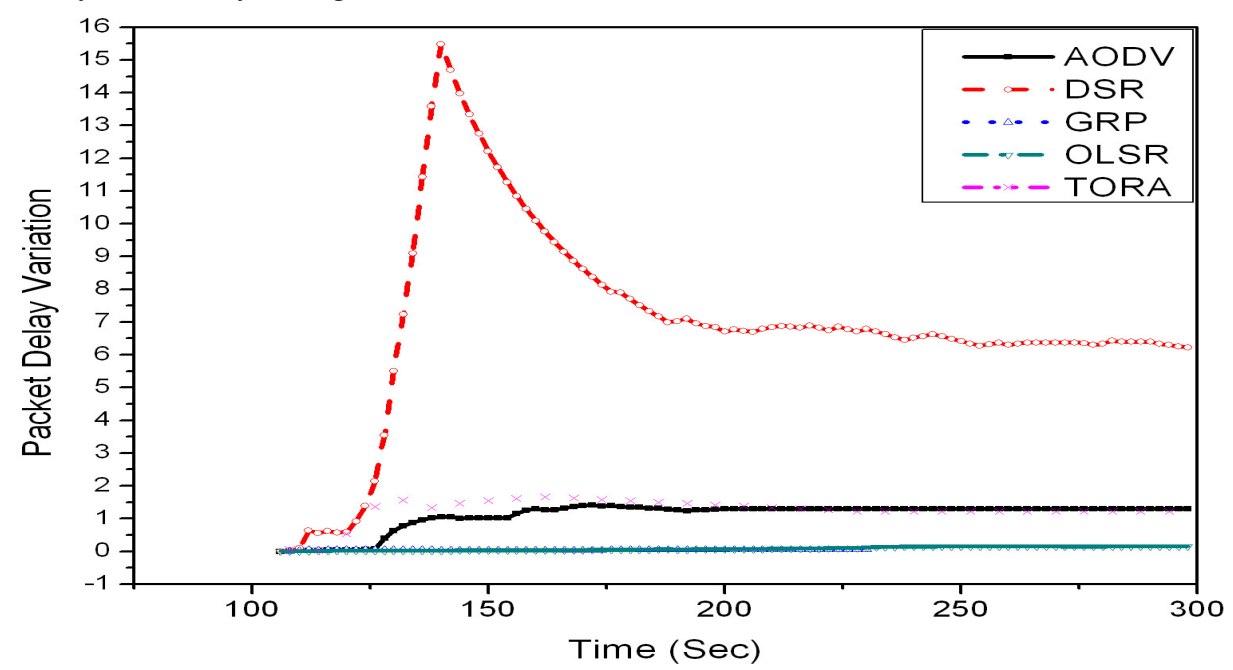

Fig. 8 Packet delay variation for the network of 85 nodes

Table-3 summarizes the performances of different routing protocols under various QoS parameters for streaming of low resolution video over MANETs for both small area and large area network. The values are considered for the video streaming time of 3 minutes over the routing protocols. 
International Journal of Computer Networks \& Communications (IJCNC) Vol.4, No.3, May 2012 Table 3: Performance analysis of different routing protocols for low resolution video transmission.

\begin{tabular}{|l|l|l|l|l|}
\hline \multicolumn{5}{|c|}{ Small area network of 25 nodes } \\
\hline $\begin{array}{l}\text { Routing } \\
\text { protocols }\end{array}$ & Throughput & $\begin{array}{l}\text { End-to-end } \\
\text { delay }\end{array}$ & $\begin{array}{l}\text { Wireless LAN } \\
\text { Delay }\end{array}$ & $\begin{array}{l}\text { Packet delay } \\
\text { variation }\end{array}$ \\
\hline DSR & 2178580.436 & 0.048720062 & 0.011918567 & 0.015280301 \\
\hline AODV & 5326496.792 & 0.035976177 & 0.024429711 & 0.010403094 \\
\hline OLSR & 3207741.624 & 0.015260856 & 0.003561012 & 0.000112644 \\
\hline GRP & 2215320.673 & 0.012244939 & 0.022799694 & 3.41877 E-05 \\
\hline TORA & 1024515.01 & 0.008935256 & 0.002110731 & $1.14597 \mathrm{E}-06$ \\
\hline & 5826723.802 & 1.198082491 & 1.670809838 & 6.706222872 \\
\hline DSR & 6981296.475 & 0.090471707 & 0.031644138 & 1.284648046 \\
\hline AODV & 14598425.03 & 0.282110772 & 0.374000909 & 0.06541059 \\
\hline OLSR & 9098749.644 & 0.075207857 & 0.388246393 & 0.044260849 \\
\hline GRP & 18299162.93 & 0.206241953 & 8712152.941 & 1.41517965 \\
\hline TORA & & & & \\
\hline
\end{tabular}

Performance of TORA protocol is satisfactory for transmitting low resolution video over MANET for both scenarios although it has low throughput in the small network but overall delay performances are acceptable. On the other DSR protocol is not suitable for video streaming but it shows good throughput performance in smaller network. On the other hand OLSR also performs well and AODV and GRP are also moderate candidates for video streaming application.

\subsection{High resolution video}

We have used high resolution video for analyzing the performances of different routing protocols over MANET environment for both the networks of 25 nodes and 85 nodes. From Fig. 9 and Fig. 10 it is shown that for small area scenario the throughput of the AODV protocol is the highest and it increases with transmission time and TORA protocol has the least throughput performance. 
International Journal of Computer Networks \& Communications (IJCNC) Vol.4, No.3, May 2012

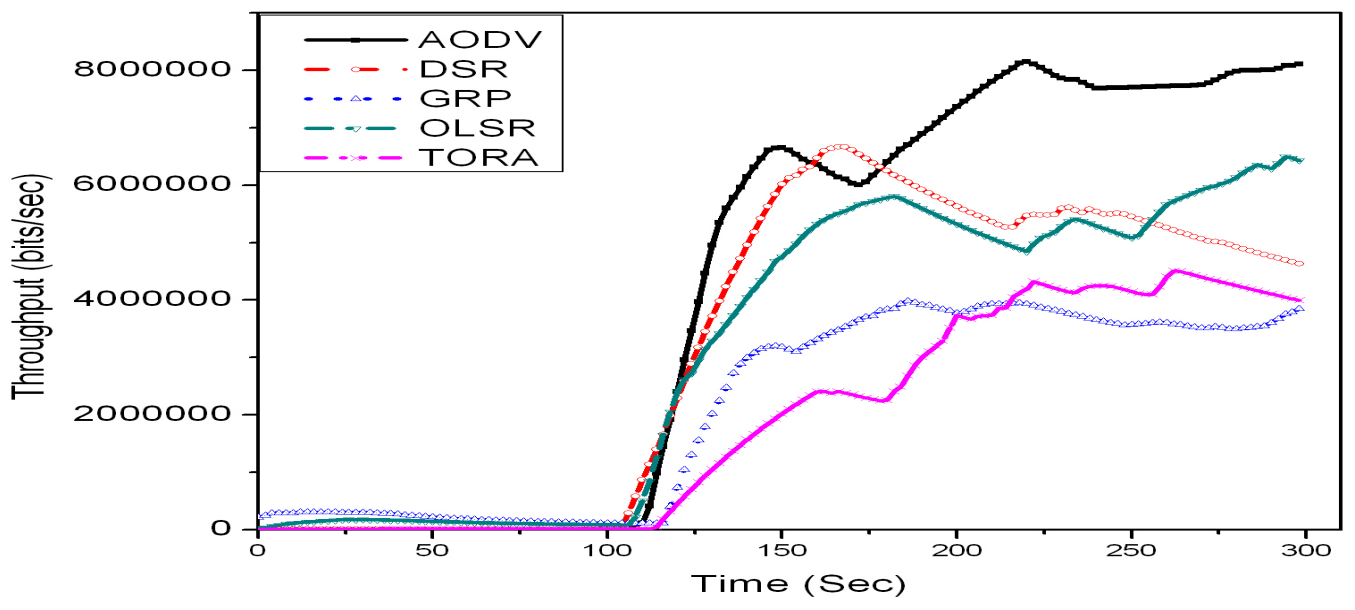

Fig. 9 Throughput for the network of 25 nodes

In the large area TORA protocol outperforms significantly over other protocols contrary to small scale network where the AODV has the least throughput for transmitting high resolution video in this case.

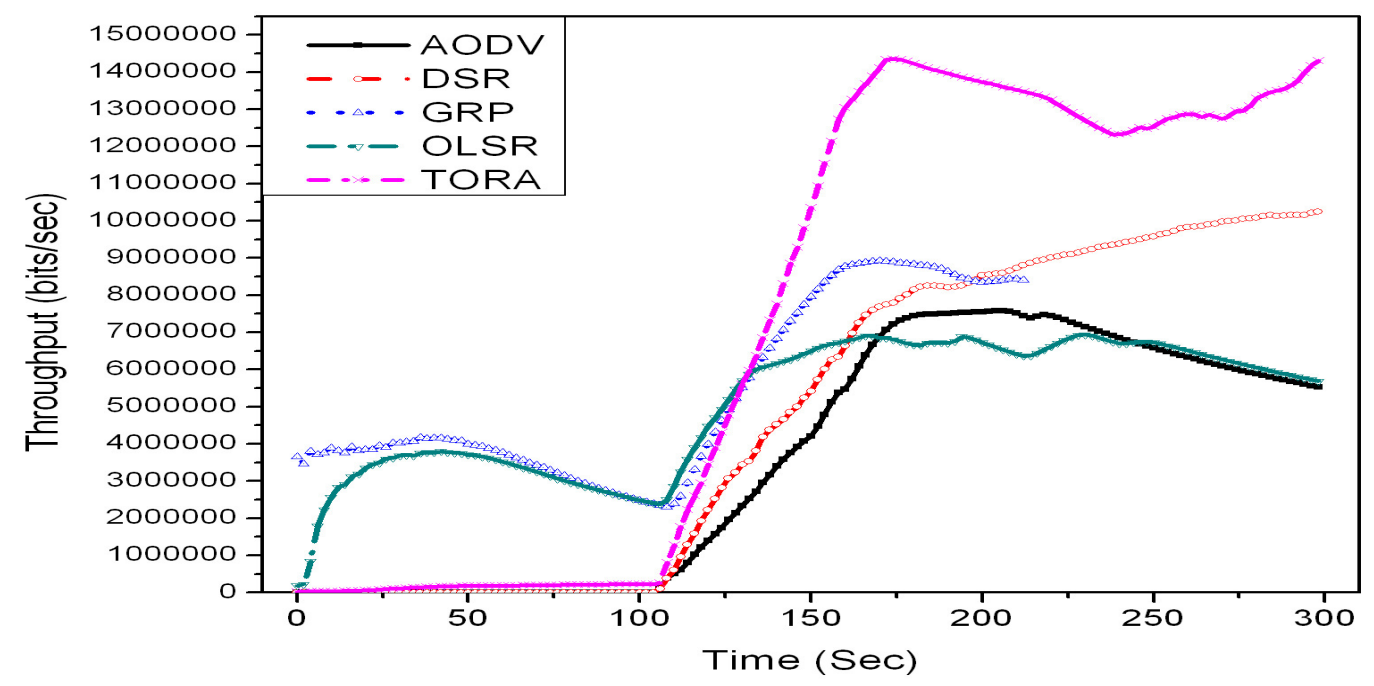

Fig. 10 Throughput for the network of 85 nodes

By examining the end-to-end delay performances presented in Fig. 11 and Fig. 12 it is observed that DSR protocol has the worst performance and it has got end-to-end delay of $0.3 \mathrm{sec}$ for small area and around 2.1 second for large area network although the delay decreases with transmission time in large area.

The performance of TORA protocol is contradictory with small and large area scenario. It has delay of about $0.25 \mathrm{sec}$ in small area and has the best performance over other protocols in large area network around $2 \mathrm{~ms}$. 
International Journal of Computer Networks \& Communications (IJCNC) Vol.4, No.3, May 2012

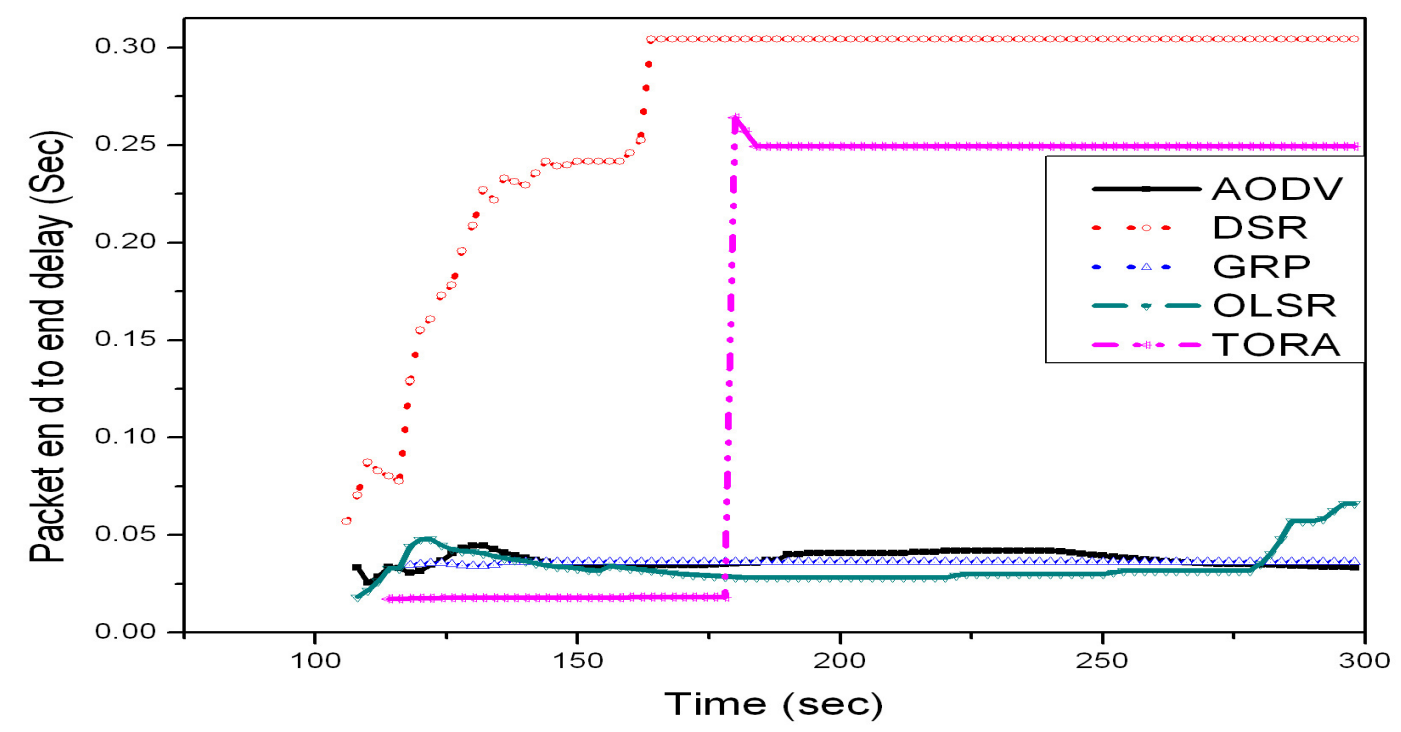

Fig. 11 Packet end-to-end delay for the network of 25 nodes.

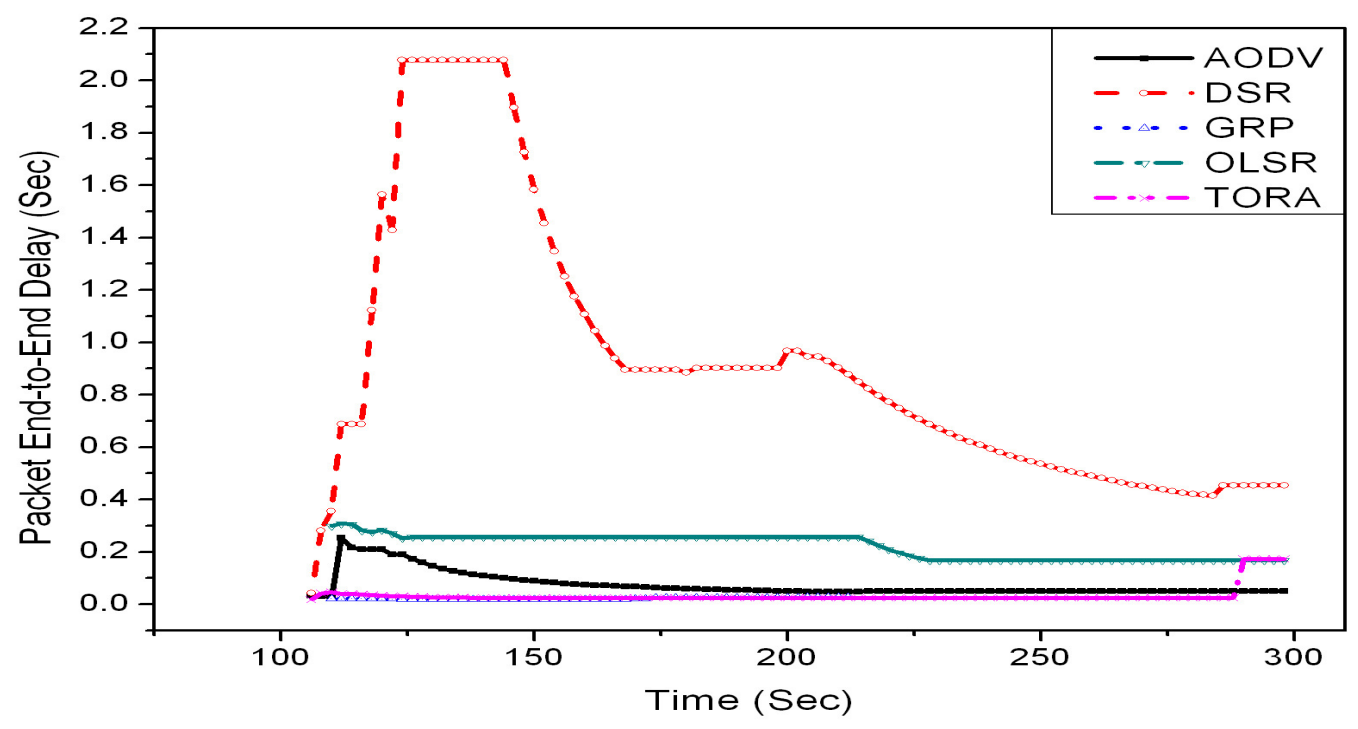

Fig. 12 Packet end-to-end delay for the network of 85 nodes.

Analyzing the performance in terms of Wireless LAN delay as depicted in Fig. 13 and Fig. 14 we can conclude that DSR protocol has the highest WLAN delay, which makes it unsuitable for transmitting

high resolution video over MANET. On the other hand the performance of TORA protocol is excellent compare to other protocols in both the scenario and WLAN delay is around $25 \mu \mathrm{s}$ in small 
International Journal of Computer Networks \& Communications (IJCNC) Vol.4, No.3, May 2012 area network and $0.7 \mu \mathrm{s}$ in large area network. AODV protocol is suitable for large area network but in small scale it performance is not suitable.

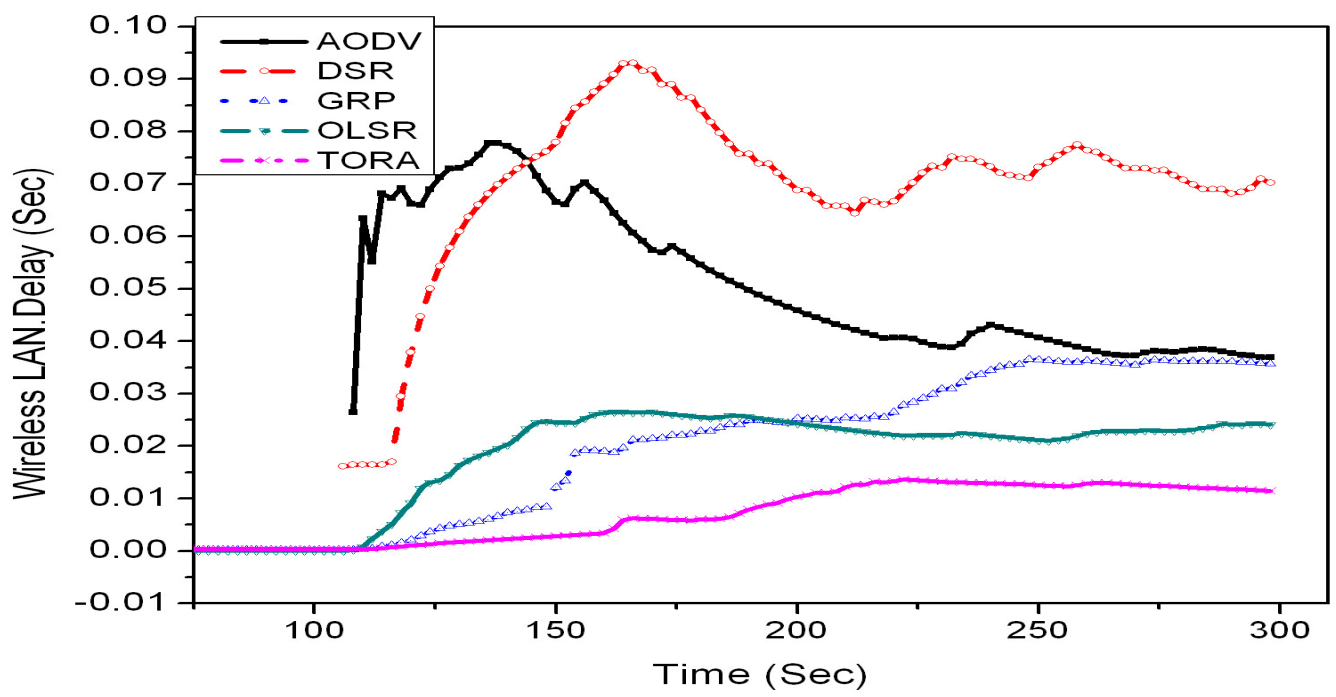

Fig. 13 Wireless LAN delay for the network of 25 nodes

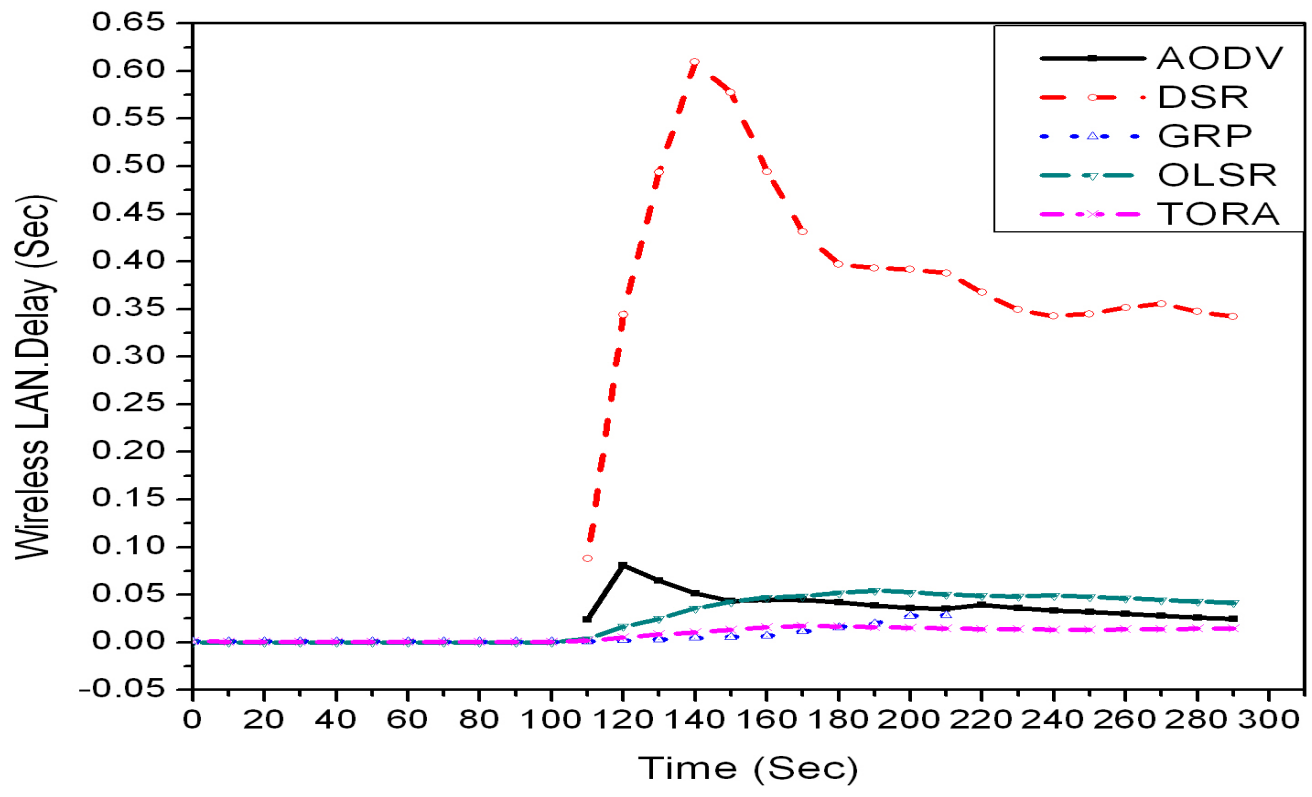

Fig. 14 Wireless LAN delay for the network of 85 nodes

If we consider the average packet delay variation as shown in Fig. 15 and Fig. 16, we can conclude that the performances of TORA, OLSR and GRP have similar packet delay variation and in the range of 0 to $5 \mathrm{~ms}$. Whereas the DSR and AODV do not perform well enough and have nonlinear average packet delay variation with transmission time. 
International Journal of Computer Networks \& Communications (IJCNC) Vol.4, No.3, May 2012

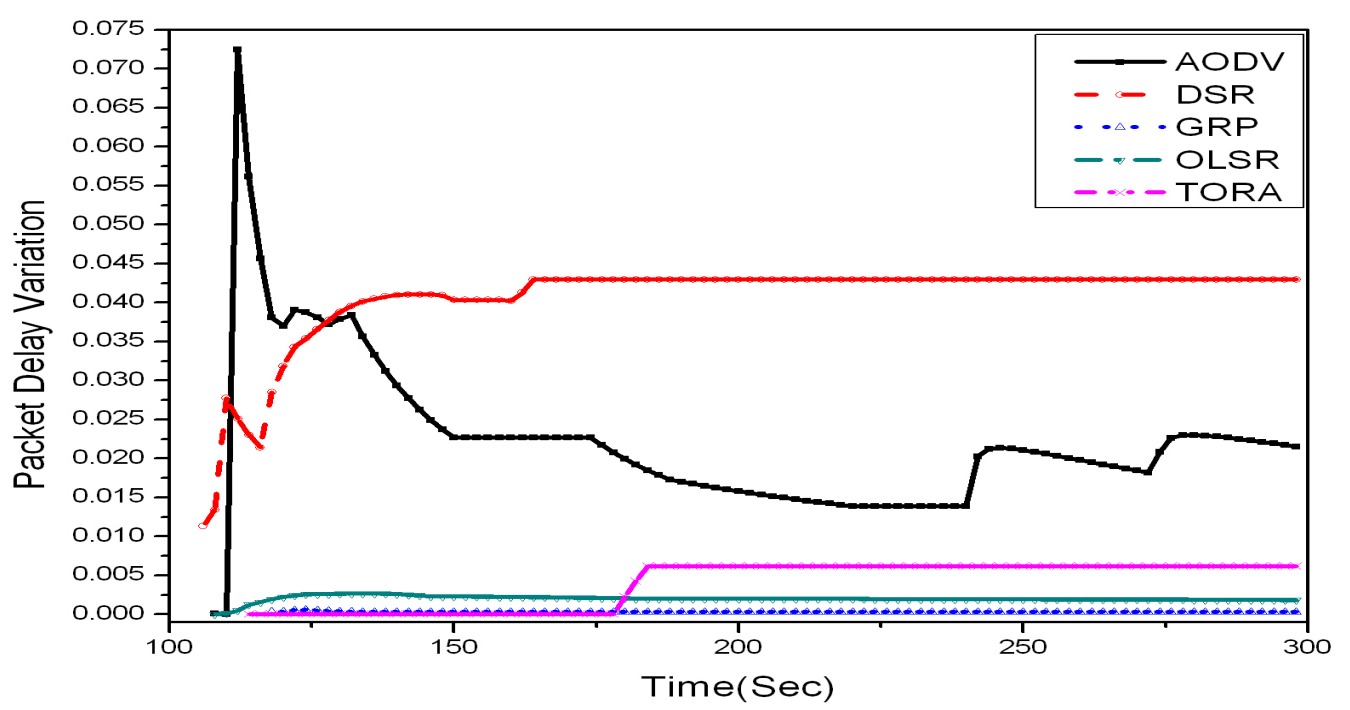

Fig. 15 Packet delay variation for the network of 85 nodes.

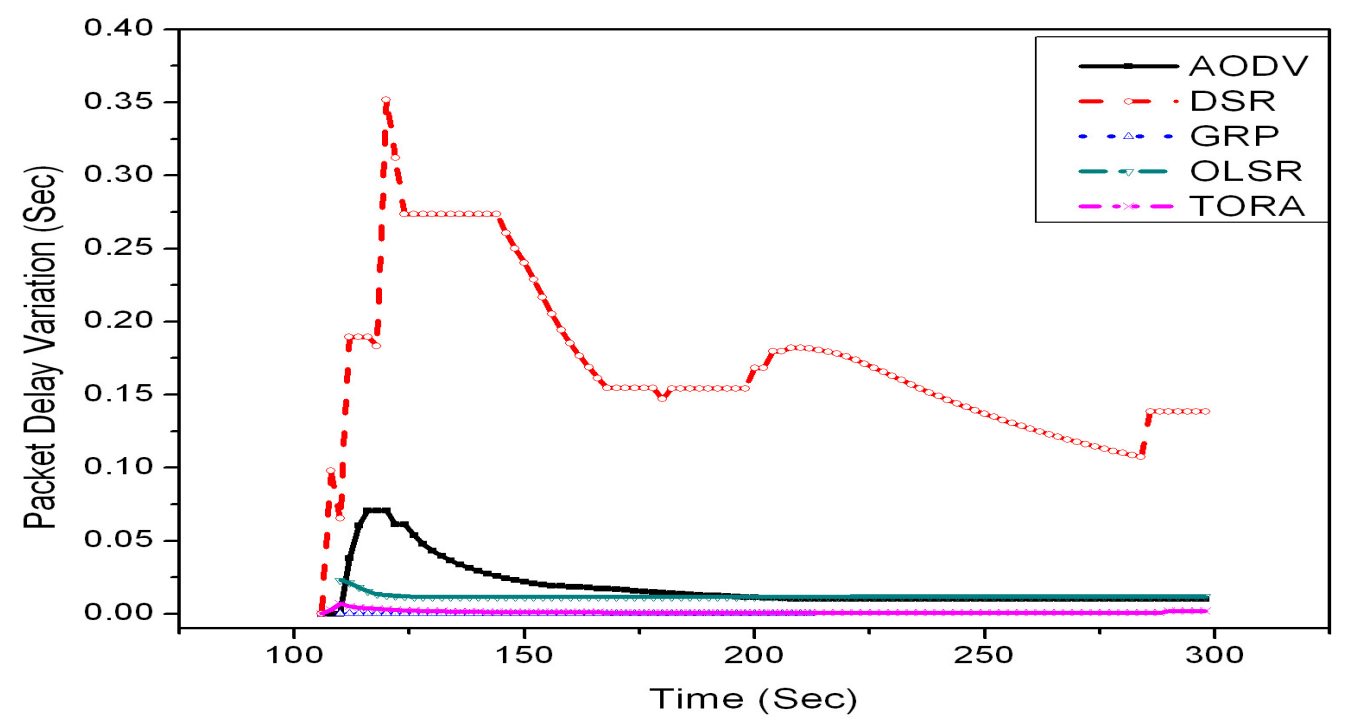

Fig. 16 Packet delay variation for 25 nodes.

Table-4 summarizes the performance of different routing protocols under various QoS parameters for streaming of high resolution video over MANETs for both small area and large area network. The values are considered for the video streaming time of 3 minutes over the routing protocols. It is obvious that also for transmitting high resolution video TORA performs better than other routing protocol we investigated but it has packet end-to-end delay for small area network is good.GRP, OLSR and AODV also performs considerably for high resolution video transmission. DSR protocols performs inadequately also for high resolution video streaming application. 
Table 4: Performance analysis of different routing protocols for high resolution video transmission.

\begin{tabular}{|l|l|l|l|l|}
\hline \multicolumn{5}{|c}{ Small area network of 25 nodes } \\
\hline $\begin{array}{l}\text { Routing } \\
\text { Protocols }\end{array}$ & Throughput & $\begin{array}{l}\text { End-to-end } \\
\text { delay }\end{array}$ & $\begin{array}{l}\text { Wireless LAN } \\
\text { delay }\end{array}$ & $\begin{array}{l}\text { Packet delay } \\
\text { variation }\end{array}$ \\
\hline DSR & 5631888,792 & 0,304387063 & 0,068811926 & 0,042970374 \\
\hline AODV & 7367412,752 & 0,040780597 & 0,045850415 & 0,015800445 \\
\hline OLSR & 5321073,743 & 0,028222243 & 0,024314982 & 0,00201771 \\
\hline GRP & 3774426,257 & 0,036328678 & 0,025330363 & 0,00028399 \\
\hline TORA & 3734067,168 & 0,249316335 & 0,01028411 & 0,006144891 \\
\hline $\begin{array}{l}\text { Routing } \\
\text { Protocols }\end{array}$ & Lhroughput & $\begin{array}{l}\text { End-to-end } \\
\text { delay }\end{array}$ & $\begin{array}{l}\text { Wireless LAN } \\
\text { delay }\end{array}$ & $\begin{array}{l}\text { Packet delay } \\
\text { variation }\end{array}$ \\
\hline DSR & 8535039,525 & 0,967500476 & 0,391501935 & 0,168200627 \\
\hline AODV & 7555503,525 & 0,050492897 & 0,035694106 & 0,011208419 \\
\hline OLSR & 6726738,218 & 0,256518723 & 0,05257914 & 0,011697321 \\
\hline GRP & 8346691,822 & 0,025845157 & 0,027718755 & 0,000117659 \\
\hline TORA & 13735215,37 & 0,024280994 & 0,015283289 & 0,000813027 \\
& & & & \\
\hline
\end{tabular}

\subsection{CONCLUSIONS}

Finally, we have concluded that it is possible to launch video streaming with acceptable quality and throughput over MANETs. The simulation results show that the performances of a routing protocol vary depending on the network scenario as well as types of video traffic used. Based on the simulation results we can conclude that the overall performance of TORA is the best as all QoS parameters have favorable results as indicated in Table 3 and 4 . TORA uses the optimizing routes function to adjust improve routing. The performance of AODV is poor compared to OLSR and GRP but better than DSR. Because of high overhead packets DSR performance degrades in heavy loads and traffic conditions. The performance of DSR protocol is poor and it should not be suggested for the video transmission. In order to find a concrete conclusion about the best routing protocol for video other numerous routing protocols need to be considered. But, this effort was limited only to some popular protocols like DSR, AODV, TORA, OSLR and GRP. 
International Journal of Computer Networks \& Communications (IJCNC) Vol.4, No.3, May 2012

\section{References}

1. S. Corson and J. Macker. "Mobile Ad Hoc Networking (MANET): Routing Protocol Performance Issues and Evaluation Consideration", available at http://www.ietf.org/rfc/rfc2501.txt

2. E.M. Royer, C-K. Toh, "A Review of Current Routing Protocols for Ad Hoc Mobile Wireless Networks", IEEE Personal Communications Magazine, April 1999, pp. 46-55.

3. R. Bai, M. Singhal, DOA: DSR over AODV Routing for Mobile Ad Hoc Networks, IEEE Transactions on Mobile Computing, Vol. 5, No. 10, 2006, pp. 1403-1416

4. M. U. Chowdhury, D. Perera, T. Pham, "A Performance Comparison of three Wireless Multihop Ad-hoc Network Routing Protocols when Streaming MPEG-4 Traffic", In Proceedings of the 8th International Multi topic Conference, 2004, pp. 516-521.

5. A. Shrestha, F. Tekiner. "On MANET Routing Protocols for Mobility and Scalability" In the Proceedings of the International Conference on Parallel and Distributed Computing, Applications and Technologies (PDCAT 2009), Higashi Hiroshima, Japan, 8-11, December 2009, pp. 451-456.

6. H. Tafazolli, "A Survey of QoS Routing Solutions for Mobile Ad Hoc Networks", IEEE Communications Surveys \& Tutorials, Vol. 9, No. 2, pp. 50-70, 2007.

7. IEEE 802.11 WG. IEEE 802.11e, Medium Access Control (MAC) Quality of Service (QoS) Enhancements. Draft Supplement to IEEE 802.11 Standard, 2005.

8. Janio M. Monteiro, Carlos T. Calafate, and Mario S. Nunes, "Evaluation of the H.264 Scalable Video Coding in Error Prone IP Networks," IEEE Transactions on Broadcasting, Vol. 54, No. 3, September 2008, pp. 652-659

9. Gyeongcheol Lee and Hwangjun Song, "Cross layer optimized video streaming based on IEEE 802.11 multi-rate over multi-hop mobile ad hoc networks," Mobile Network Application, Vol. 15 , October 2010, pp. 652-663

10. Tarek Sheltami, "Performance Evaluation of H.264 Protocol in Ad hoc Networks," Journal of Mobile Multimedia, Vol. 4, No. 1, 2008, pp. 59-70

11. Carlos T. Calafate, M. P. Malumbres, P. Manzoni," Performance of H.264 compressed video streams over $802.11 \mathrm{~b}$ based MANETs," In the Proceedings of the $24^{\text {th }}$ International Conference on Distributed Computer System Workshops, March 2004, pp. 776-781

12. Jose L. Muñoz *, Oscar Esparza, Mónica Aguilar, Victor Carrascal, Jordi Forné,” RDSR-V. Reliable Dynamic Source Routing for video-streaming over mobile ad hoc networks." Journal of computer networks, 2010, Vol. 54, pp.79-96

13. Elsa Mac'ias, Member, IAENG, Alvaro Su'arez, Member, IAENG, J. Mart'in and Vaidy Sunderam," Using OLSR for Streaming Video in 802.11 Ad-Hoc Networks to Save Bandwidth.” IAENG International Journal of Computer Science, Vol. 33, No. 1, 2007

14. Ronald Beaubrun and Badji Molo, "Using DSR for routing multimedia traffic in MANETs," International journal of Computer Networks and Communications (IJCNC), January 2010, Vol.2, No.1, pp. 120-138

15. Aftab Ahmad. “Wireless and Mobile Data Networks.” John Wiley \& Sons, Inc., Hoboken, NJ, USA, 2005.

16. Anurag Malik, Shivanshu Rastogi, Sajendra Kumar," Performance Analysis of Routing Protocol in MobileAd Hoc Network using NS-2." MIT International Journal of Computer Science \& Information Technology, January 2011, Vol. 1 No. 1, pp. 47-50.

17. Mohammed Tarique, Kemal E. Tepe, Sasan Adibi and Shervin Erfani, “ A survey on the multipath routing protocols for mobile ad hoc networks", Journal of Networks and Computer Applications, Vol. 32, No.6, November 2009, pp.1125-1143 
International Journal of Computer Networks \& Communications (IJCNC) Vol.4, No.3, May 2012

18. Muhammad Shaffatul Islam, Md. Nazmul Islam, Md. Shah Alam, Md. Adnan Riaz, Md. Tanvir Hasan, "Performance evaluation of various vocoders in Mobile Ad hoc Network (MANET)," In the Proceedings of the 6th International Conference on Electrical and Computer Engineering ( ICECE) 2010, pp. 18-20

19. C. E. Perkins, E. M. Belding-Royer, and S. R. Das, "Ad hoc On-Demand Distance Vector (AODV) routing,” Internet Engineering Task Force (IETF) draft, November 2002.

20. Vincent D. Park and M. Scott Corson, "A performance comparison of the Temporally-Ordered Routing Algorithm (TORA) and Ideal Link-State Routing", In the Proceedings of IEEE symposium on Computer and Communication, June 1999

21. T. Clausen, and P. Jacquet, "Optimized Link State Routing Protocol (OLSR)”, IETF, RFC 3626, 2003.

22. H. Badis, and K. Al Agha, "QOLSR, QoS routing for Ad Hoc Wireless Networks Using OLSR". In European Transactions on Telecommunications, Vol. 16, No. 5, 2005, pp. 427-442

23. Jain, R., Puri, A. and Sengupta, R., "Geographical Routing Using Partial Information for Wireless Ad Hoc Networks,” IEEE Personal Communications Magazine, Vol. 8, No. 1, Feb. 2001, pp. 48-57,

24. M. Mauve, J. Widmer, H. Hartenstein, "A Survey on Position-based Routing in Mobile Ad hoc Networks", IEEE Network Magazine, 2001, Vol. 15, No. 6, pp. 30-39. 